DOI: 10.38136/jgon.722902

\title{
Gebelerin Gebeliği İsteme Durumuna Göre Aleksitimik Özelliklerinin Karşılaştırılması
}

\section{Comparison Of Pregnancies Alexithymic Characteristics Based On Pregnancy Intention}

\author{
Tuğçe SÖNMEZ \\ Serap Ejder APAY 2 \\ Sibel TEKGÜNDÜZ \\ Cantürk ÇAPIK ${ }^{4}$
}

(1) Orcid ID:0000-0001-9495-526X

(1) Orcid ID:0000-0003-0978-1993

(1) Orcid ID:0000-0002-8146-643X

(1) Orcid ID:0000-0002-2020-6239

\author{
${ }^{1}$ Gaziantep İslam Bilim ve Teknoloji Üniversitesi Sağlık Bilimleri Fakültesi, Ebelik Bölümü, Gaziantep \\ ${ }^{2}$ Atatürk Üniversitesi Sağllık Bilimleri Fakültesi, Ebelik Bölümü, Erzurum \\ ${ }^{3}$ Nenehatun Kadın Doğum Hastanesi, Erzurum \\ ${ }^{4}$ Atatürk Üniversitesi Hemșirelik Fakültesi, Halk Sağlı̆ı Hemșireliği Anabilim Dalı, Erzurum
}

\section{Öz}

Amaç: Bu araştırma gebeliğini isteyen ve istemeyen gebelerin aleksitimi düzeylerini karşılaştırmak amacıyla yapılmıştır.

Gereç ve Yöntem: Araştırma tanımlayıcı ve ilişki arayıcı nitelikte olup Türkiye'nin doğusunda bir doğum hastanesinde yapıımıştır. Araştırmada örneklem seçimine gidilmeden araştırmaya katılmaya gönülü olan 446 (Gebelik isteyen:222, Gebelik istemeyen:224) gebe araştırma kapsamına alınmıştır.

Veriler Temmuz-Ağustos 2016 tarihleri arasında Kişisel Bilgi Formu ve Toronto Aleksitimi Skalası (TAS-20) kullanılarak toplanmıştır. Veriler SPSS paket programında yüzdelik dağılımlar, ortalama, ki-kare ve bağımsız gruplarda t-testi kullanılarak değerlendirilmiştir.

Bulgular: Araştırmaya alınan gebelerin sosyo-demografik özelliklerinin benzer olduğu ve istatistiksel olarak anlamlı bir fark olmadığı bulunmuştur ( $p>0.05$ ). Gebeliğini isteyen kadınların Toronto Aleksitimi Skala puan ortalaması $65.04 \pm 11.83$, gebeliğini istemeyen kadınların ise $65.37 \pm 11.15$ olarak bulunmuştur. Gebeliğini isteyen ve istemeyen kadınların Toronto Aleksitimi Skalası puan ortalamaları karşılaştıııdığında; grupların puan ortala?maları arasındaki farkın istatistiksel olarak anlamlı olmadığı bulunmuştur ( $p>0.05)$.

Sonuç: Gruplar sosyo-demografik özellikler yönünden homojendir ve gebeliğini isteyen ve istemeyen kadınların aleksitimi düzeyleri arasında bir fark görülmemiştir.

Anahtar Sözcükler: Aleksitimi, ebe, gebelik, gebeliği isteme, gebeliği istememe

\section{GíRiş}

Gebelik, kadın için doğal bir yaşam olayı olmanın yanı sıra önemli biyopsikososyal değişimlerin yaşandığı, kaygı ve stres oluşturabilecek birçok etkenle karşılaşma riskinin yüksek olduğu bir süreçtir (1). Literatürde gebelik

\section{ABSTRACT}

Aim: This study was conducted to compare alexithymia levels of pregnant women intending and not intending their pregnancy.

Material and Methods: This descriptive and correlational study was conducted at a maternity hospital in eastern Turkey. 446 pregnant women (intending pregnancy:222, not intending pregnancy:224) who were voluntary to participate in the study were included in the study without making any sample selection.

The data were collected by using Personal Information Form and Toronto Alexithymia Scale (TAS-20) between July and August 2016. The data were assessed by using percentage distributions, mean, chi-square, and independent samples t-test in SPSS packaged software.

Results: It was found that the pregnant women included in the study had similar socio-demographic characteristics and there was no statistically significant difference $(p>0.05)$. While mean score obtained by the women intending their pregnancy from Toronto Alexithymia Scale was $65.04 \pm 11.83$, mean score of the women not intending their pregnancy for Toronto Alexithymia Scale was $65.37 \pm 11$.15. When mean scores of women intending and not intending their pregnancy for Toronto alexithymia Scale were compared, it was determined that the difference between mean scores of the groups was not statistically significant $(p>0.05)$. Conclusion: The groups were homogenous in terms of socio-demographic characteristics and no difference was observed between alexithymia levels of women intending and not intending their pregnancy.

Keywords: Pregnancy, alexithymia, pregnancy intention, pregnancy unintention, midwife

ve doğumun neden olduğu nöroendokrin ve psikososyal değişiklerin yaşamın diğer dönemleriyle karşılaştırmanın mümkün olamayacağı ifade edilmektedir (2,3). Gebelik kadınların yaşamında stres faktörü olursa endişe ve depresyonla birleşebilir $(3,4)$. Gebelikte mevcut psikiyatrik semptomlarda alevlenme görülebilirken, ilk psikiyatrik semptomlar gebelik sırasında da or- 
taya çıkabilmektedir (5). Bu nedenle gebelik, kadınların depresyon, anksiyete bozukluğu vb. psikiyatrik hastalıklara yatkınlığının artabileceği bir süreçtir (6). Bu süreçte kadın duygu dalgalanmaları içerisinde olabilir ve hatta gebeliğini istemeyebilir. İlk trimesterde istenmeyen gebelikler, anksiyete ve depresyonla ilişkilidir $(7,8)$. Gebelikte meydana gelen ruhsal bozukluklar daha çok ikinci trimesterde işlevsellik kaybı, olumsuz prenatal bağlanma, yaşam kalitesinin bozulması ve hatta intihar olarak ortaya çıkmaktadır $(7,8)$. Bu nedenle bu dönem ruhsal bozukluklar açısından risk daha dikkatli değerlendirimelidir. Üçüncü trimesterde ise sorunlar hala devam ediyorsa ruhsal bozuklar daha çok artacak ve doğum sonu dönemde de devam edecektir $(7,8)$. Bazı çalışmalar aleksitiminin ortaya çıkmasında depresyonun güçlü bir etkisi olduğunu savunmaktadır $(9,10)$. Bu yüzden gebelerin gebeliklerini isteyip istemediklerinin öğrenilmesi ileriki ruhsal değişimlerde bize önemli katkı sağlayacaktır.

Duyguları açığa çıkarma, fiziksel ve psikolojik sağlık açısından oldukça önemlidir. Birey, duygularını hissetmek ve yaşamak konusunda kendisini bastırıyor ya da savunmacı davranıyorsa, duygusal farkındalığı düşük bir düzeydeyse ya da duygularını ifade etmek için kısıtı sözcük dağarcığına sahipse bireyin sadece duygularını açığa çıkarma kapasitesi kısıtlanmayacak aynı zamanda sağlığı da olumsuz yönde etkilenecektir (11). Duyguların ifade edilmesine dair çalışmalar 1940'lı yılların sonlarında başlamıştır (12). Bu yıllarda duyguların ifadesi konusunda bazı hastaların sıkıntı yaşadıklarına dair gözlemler yapılmaya başlanmışıı (12). Ruesch, klasik psikosomatik ya da diğer kronik hastalıkları olan hastaların, hayal gücünden yoksun olduklarını, duyguların sözel ve sembolik ifadesinde açıkça fark edilen güçlükler yaşadıklarını ve bu nedenle psikonevrotik hastalardan açıkça farklı olduklarını gözlemlemiştir $(12,13)$. Olgunlaşmamış bu ifade güçlüğünün fizyolojik semptomlar olarak kendini göstermesi nedeniyle de "çocuksu kişilikler" olarak tanımlamıştır. MacLean de psikosomatik hastaların duygularını sözelleştiremediğini; aynı zamanda neokortekse geçirilemeyen duyguların ifade edilememesi sonucunda otonom sistemin devreye girerek bir anlamda "organ dili”ne dönüşen fizyolojik belirtilerin söz konusu olduğunu belirtmiştir $(12,13)$. 1950 'lerde Freedman ve Sweet ise bu gruptaki duyguların ifade edemeyen hastaları "duygu cahilleri" olarak tanımlamıştır $(12,13)$. 1960'larda literatürde benzer çalışmalar bulunmaktadır. Marty ve M'Uzan psikosomatik hastalarda "operasyonel/işevuruk düşünme" olduğunu belirtmişlerdir (14). Şaşıŏlu ve ark. aktardığına göre; 1970'lerde Nemiah ve Sifneos'un, çeşitli psikosomatik yakınmaları olan hastalarda duygulanım bozukluğu üzerine sistematik olarak yaptıkları klinik gözlemlerinin sonucunda, bazı danışanlarının duygularını tanıması, ifade edebilmesi ve aynı zamanda sözelleştirebilmesi konusunda güçlük yaşayabildikleri saptanmıştır (15). "Duygular İçin Söz Yokluğu" anlamına gelen aleksitimi kavramı 1972'de Sifneos tarafından literatüre kazandırıımıştır (15).

Aleksitimi, düşlem ve fantezi yaşamındaki kısıtlılık, duygu, düşünce ve fizyolojik tepkileri ayırt etmedeki yetersizlik ve duyguları tanıma ve ifade etmedeki güçlükler olarak tanımlanmaktadır (16-18). Başlangıçta psikosomatik hastalarda görülen belirtileri açıklamak için kullanılmış olsa da, günümüzde sağlıkı popülasyonda da karşımıza çıkan bir kişilik özelliği olarak kabul görmektedir (16-18). Yapılan çalışmalarda aleksitiminin sağlıkı popülasyondaki prevalansı \%10'nun üzerinde bulunmuştur (19-21). İran'da ki gebe kadınların aleksitimi prevalansı \%27.9 olarak saptanmıştır (22). Aleksitimi anne-bebek arasındaki iletişimde negatif bir etkiye sahiptir ve çocukların psikososyal gelişimlerini olumsuz etkiler (23).

Literatür incelemesi sonucunda yapılan çalışmalara bakıldığında gebeler üzerinde aleksitimik özellikleri içeren çalışmalar görülmemektedir. Bu nedenle bu çalışma gebeliğini isteyen ve istemeyen gebelerin aleksitimi düzeylerini karşılaştırmak amacıyla planlanmıştır.

\section{GEREÇ VE YÖNTEM}

Bu çalışma tanımlayıcı ve ilişki arayıcı nitelikte yapııdı. Araştırma Erzurum ilindeki Nenehatun Kadın Doğum Hastanesi Kadın Doğum Polikliniği'nde Temmuz-Ağustos 2016 tarihleri arasında başvuran gebeler üzerinde yapıldı. Bu hastane bir bölge hastanesi niteliğinde olması ve hasta yoğunluğu nedeniyle seçilmiştir.

Araştırmanın evrenini, Erzurum ilindeki Nenehatun Kadın Doğum Hastanesi Kadın Doğum Polikliniği'ne Temmuz-Ağustos 2016 tarihleri arasında başvuran gebeler oluşturmuştur. Araştırmanın örneklemini ilgili polikliniklere belirtilen tarihler arasında başvuran, herhangi bir kronik rahatsızıı̆ı bulunmayan, son trimester ve çalışmaya katılmayı kabul eden toplam 446 gebe dahil edildi. Kronik bir rahatsızıı̆ı olan ve klinik takibi için ayrılmak zorunda kalan gebeler çalışma dışı bırakıımıştır.

Araştırma verilerinin toplanmasında Anket Formu ve Toronto Aleksitimi Skalası (TAS-20) kullanıldı.

Anket Formu: Araştırmacılar tarafından hazırlanan ve gebelerin sosyo-demografik ve obstetrik öykülerini içeren 14 sorudan oluşmaktadır $(1,3,4,23)$.

Toronto Aleksitimi Ölçeği (TAÖ): Kişinin kendi duygu ve heyecanlarını tanımaması olarak tanımlanan aleksitimiyi değerlendirmede kullanılan ölçek, Bagby ve arkadaşları (1994) tarafından geliştirilmiştir. Türkçe geçerlilik ve güvenilirliği Sayar ve arkadaşları (2001) tarafından yapılmıştır (24-26). TAÖ 20 maddeden ve üç alt boyuttan (Duygularını tanımada güçlük (TAÖ-1), duyguları söze dökmede güçlük (TAÖ-2), dışa-dönük düşünme (TAÖ-3)) oluşmaktadır. Ölçek likert tipte olup, 1-5 arası puanlanmaktadır. Bireyden, her madde için "Hiçbir zaman", "Nadiren", "Bazen", "Sık sık" ve "Her zaman" seçeneklerinden en uygununu işaretlemesi istenir. Yüksek puanlar yüksek aleksitimik seviyeyi gösterir.

Veriler Temmuz-Ağustos 2016 tarihleri arasında araştırmacı tarafından yüz yüze görüşme tekniği ile toplandı. Gebeler araştırmaya katımaları için davet edilirken Gönüllü Olur Formundaki bilgiler okunarak sözlü onamları alındı. Formlar uygulanmadan önce gebelere araştırma hakkında bilgi verildi. Verilerin toplanması her bir gebe için yaklaşık 10-15 dakika sürmüştür. Veriler SPSS paket programında yüzdelik dağııımlar, ortalama, ki-kare ve bağımsız gruplarda t-testi kullanılarak değerlendirildi.

Araştırmaya başlamadan önce, Erzurum Atatürk Üniversitesi Sağlık Bilimleri Fakültesi Etik Kurulu'ndan onay (2016/07/17 sayı 15/07/2016 tarih) ve araştırmanın yapılacağı hastaneden gerekli izinler alındı. Katıımcılardan bilgi alınarak yapılan tüm araştırmalarda cevapların gönüllü olarak verilmesi gerektiğinden, araşıırmaya alınacak gebelerin gönüllü ve istekli olmalarına özen gösterilerek, araşıımaya katılıp katılmama konusunda özgür oldukları açıklandı. Araştırma verilerini toplamaya başlamadan önce; gebelere araştırma hakkında bilgi verilip, araşı̧ımaya ilişkin soruları yanıtlanmış, gebelerin sözel onayları alınarak 'Bilgilendirilmiş Onam İlkesi' yerine getirildi. Gebelerin istedikleri zaman araştırmadan çekilebilecekleri belirtilerek "Özerklik IIlkesine", bireysel bilgilerin araştırmacı ile paylaşıldıktan sonra korunacağı söylenerek "Gizlilik ve Gizliliğin Korunması ilkesine" uyulmasına özen gösterildi. Elde edilen bilgilerin ve cevaplayanın kimliğinin gizli tutulacağı belirtilerek "Kimliksizlik ve Güvenlik ilkesi" yerine getirildi.

\section{BULGULAR}

fik özelliklere göre dağııımı Tablo 1'de verilmiştir. Gebeliğini isteyen gebelerin \%52.3'ünün 26-35 yaş aralığında, \%59.9'unun ilköğretim mezunu, \%55.9'unun evlenme yaşının 20-25 yaş aralığında, \%49.5'inin evlilik süresinin 2-24 ay olduğu ve \%90.5'inin çalışmadığı, \%64.9'unun gelirinin giderine eşit olduğu, $\% 66.6$ 'sının ilde ve \%70.3'ünün geniş ailede yaşadığı bulunmuştur. 
Gebelerin eşlerinin \%54.0'ının 28-37 yaş aralığında, \%59.9'unun ilköğretim mezunu ve \% 97.3'ünün çalıştığı saptanmıştır. (Tablo 1).

Gebeliğini istemeyen gebelerin \%53.6'sının 26-35 yaş aralığında, \%63.4'ünün ilköğretim mezunu, \%37.1'inin evlenme yaşının 14-19 yaş aralığında, $\% 44.2$ 'sinin evlilik süresinin 49 ay ve üstü olduğu, $\% 94.6$ 'sının çalışmadığı, $\% 62.5$ 'inin gelirinin giderine eşit olduğu, $\% 58.5$ 'inin ilde ve $\% 69.6$ 'sının çekirdek ailede yaşadığı bulunmuştur. Gebelerin eşlerinin \%56.2'sinin 28-37 yaş aralığında, \%63.4'ünün ilköğretim mezunu ve \%93.8'inin çalıştığı bulunmuştur (Tablo 1).

Tablo 1. Grupların tanıtıcı özelliklerinin karşılaştıııması

\begin{tabular}{|c|c|c|c|c|c|}
\hline \multirow[t]{2}{*}{ Tanıtıcı Özellikler } & \multicolumn{2}{|c|}{$\begin{array}{l}\text { Gebeliği isteyen } \\
(\mathrm{n}=222)\end{array}$} & \multicolumn{2}{|c|}{$\begin{array}{l}\text { Gebeliği istemeyen } \\
(\mathrm{n}=\mathbf{2 2 4})\end{array}$} & \multirow[t]{2}{*}{ Test ve p değer } \\
\hline & n & $\%$ & n & $\%$ & \\
\hline \multicolumn{6}{|l|}{ Yaş } \\
\hline $16-25$ & 88 & 39.6 & 80 & 35.7 & $X^{2}=1.29$ \\
\hline $26-35$ & 116 & 52.3 & 120 & 53.6 & $p=0.52$ \\
\hline 36 ve üstü & 18 & 8.1 & 24 & 10.7 & \\
\hline \multicolumn{6}{|l|}{ Eş Yaş } \\
\hline $18-27$ & 69 & 31.1 & 55 & 24.6 & $X^{2}=3.03$ \\
\hline $28-37$ & 120 & 54.0 & 126 & 56.2 & $p=0.21$ \\
\hline 38 ve üstü & 33 & 14.9 & 43 & 19.2 & \\
\hline \multicolumn{6}{|l|}{ Eğitim Durumu } \\
\hline Okur-yazar & 13 & 5.9 & 23 & 10.3 & \\
\hline İlköğretim & 133 & 59.9 & 142 & 63.4 & $\mathrm{X}^{2}=6.95$ \\
\hline Lise & 35 & 15.7 & 34 & 15.2 & $\mathrm{p}=0.07$ \\
\hline Üniversite & 41 & 18.5 & 25 & 11.2 & \\
\hline \multicolumn{6}{|l|}{ Eş Eğitim Durumu } \\
\hline Okur-yazar & 14 & 6.3 & 12 & 5.4 & $\mathrm{X}^{2}=3.95$ \\
\hline İlköğretim & 72 & 32.4 & 93 & 41.5 & $\mathrm{p}=0.26$ \\
\hline Lise & 77 & 34.7 & 67 & 29.9 & \\
\hline Üniversite & 59 & 26.6 & 52 & 23.2 & \\
\hline \multicolumn{6}{|l|}{ Evlenme Yaşı } \\
\hline $14-19$ & 62 & 27.9 & 83 & 37.1 & $\mathrm{X}^{2}=4.39$ \\
\hline $20-25$ & 124 & 55.9 & 112 & 5.0 & $\mathrm{p}=0.11$ \\
\hline 26 ve üstü & 36 & 16.2 & 29 & 12.9 & \\
\hline \multicolumn{6}{|l|}{ Evlilik Süresi } \\
\hline $2-24$ ay & 110 & 49.5 & 93 & 41.5 & $X^{2}=2.96$ \\
\hline $25-48$ ay & 29 & 13.1 & 32 & 14.3 & $\mathrm{p}=0.22$ \\
\hline 49 ay ve üstü & 83 & 37.4 & 99 & 44.2 & \\
\hline \multicolumn{6}{|l|}{ Çalışma Durumu } \\
\hline Çalışan & 21 & 9.5 & 12 & 5.4 & $\mathrm{X}^{2}=2.73$ \\
\hline Çalışmayan & 201 & 90.5 & 212 & 94.6 & $\mathrm{p}=0.09$ \\
\hline
\end{tabular}

\begin{tabular}{|l|l|l|l|l|l|}
\hline Eş Çalışma Durumu & & & & & \\
\hline Çalışan & 216 & 97.3 & 210 & 93.8 & $\mathrm{X}^{2}=3.27$ \\
\hline Çalışmayan & 6 & 2.7 & 14 & 6.2 & $\mathrm{p}=0.07$ \\
\hline Gelir Durumu Algısı & & & & & \\
\hline Gelir giderden fazla & 44 & 19.8 & 34 & 15.2 & $\mathrm{X}^{2}=4.37$ \\
\hline Gelir gidere eşit & 144 & 64.9 & 140 & 62.5 & $\mathrm{p}=0.11$ \\
\hline Gelir giderden az & 34 & 15.3 & 50 & 22.3 & \\
\hline Yaşanılan Yer & & & & & \\
\hline İl & 148 & 66.6 & 131 & 58.5 & $\mathrm{X}^{2}=3.41$ \\
\hline İlçe & 37 & 16.7 & 43 & 19.2 & $\mathrm{p}=0.18$ \\
\hline Köy & 37 & 16.7 & 50 & 22.3 & \\
\hline Aile Tipi & & & & & \\
\hline Çekirdek aile & 156 & 70.3 & 156 & 69.6 & $\mathrm{X}^{2}=0.02$ \\
\hline Geniş aile & 66 & 29.7 & 68 & 30.4 & $\mathrm{p}=0.88$ \\
\hline
\end{tabular}

Araştırmaya katılan gebeliğini isteyen ve istemeyen gebelerin obstetrik özelliklerine göre dağılımı Tablo 2 de verilmiştir.

Gebeliğini isteyen gebelerin \%71.6'sının ilk gebelik yaşının 18-25 yaş aralığında \%74.3'ünün 1-2 gebeliği olduğu, \%61.7'sinin yaşayan, \%92.8'inin ölen çocuğunun olmadığı, \%96.8'inin ölü doğum yapmadığı, \%87.6'sının düşük ve \%94.6'sının kürtajının olmadığı bulunmuştur (Tablo 2).

Gebeliğini isteyemeyen gebelerin \%77.2'sinin ilk gebelik yaşı 18-25 yaş aralığında, \%56.2'sinin 1-2 gebeliği olduğu, \%43.7'sinin yaşayan, \%94.6'sının ölen çocuğunun olmadığı, \%96.4'ünün ölü doğumu yapmadığı, \%78.6'sının düşük ve \%90.6'sının kürtajının olmadığı bulunmuştur (Tablo 2).

Tablo 2. Grupların obstetrik özelliklerinin karşılaştırılması

\begin{tabular}{|c|c|c|c|c|c|}
\hline \multirow[t]{2}{*}{ Obstetrik Özellikler } & \multicolumn{2}{|c|}{$\begin{array}{l}\text { Gebeliği isteyen } \\
(\mathrm{n}=222)\end{array}$} & \multicolumn{2}{|c|}{$\begin{array}{l}\text { Gebeliği istemeyen } \\
(\mathrm{n}=\mathbf{2 2 4})\end{array}$} & \multirow[t]{2}{*}{ Test ve p değeri } \\
\hline & n & $\%$ & n & $\%$ & \\
\hline \multicolumn{6}{|l|}{ İlk gebelik yaş1 } \\
\hline \multirow{2}{*}{$<18$} & 7 & 3.2 & 11 & 4.9 & $X^{2}=4.14$ \\
\hline & 159 & 71.6 & 173 & 77.2 & $\mathrm{p}=0.24$ \\
\hline $18-25$ & 53 & 23.9 & 38 & 17.0 & \\
\hline \multicolumn{6}{|l|}{$\begin{array}{l}26-35 \\
36 \text { ve üstü }\end{array}$} \\
\hline \multicolumn{6}{|l|}{ Gebelik sayısı } \\
\hline \multirow{2}{*}{$1-2$} & 165 & 74.3 & 126 & 56.2 & $\mathrm{X}^{2}=17.28$ \\
\hline & 39 & 17.6 & 58 & 25.9 & $p=0.00$ \\
\hline $3-4$ & 18 & 8.1 & 40 & 17.9 & \\
\hline
\end{tabular}




\begin{tabular}{|c|c|c|c|c|c|}
\hline \multicolumn{6}{|l|}{ Yaşayan çocuk sayısı } \\
\hline 0 & 137 & 61.7 & 98 & 43.7 & $X^{2}=19.83$ \\
\hline 1 & 52 & 23.4 & 59 & 26.4 & $\mathrm{p}=\mathbf{0 . 0 0}$ \\
\hline 2 ve üstü & 33 & 14.9 & 67 & 29.9 & \\
\hline \multicolumn{6}{|l|}{ Ölen çocuk sayısı } \\
\hline 0 & 206 & 92.8 & 212 & 94.6 & $X^{2}=0.64$ \\
\hline 1 ve üstü & 16 & 7.2 & 12 & 5.4 & $\mathrm{p}=0.42$ \\
\hline \multicolumn{6}{|l|}{ Ölü doğum sayıs1 } \\
\hline 0 & 215 & 96.8 & 216 & 96.4 & $\mathrm{X}^{2}=0.06$ \\
\hline 1 & 7 & 3.2 & 6 & 3.6 & $\mathrm{p}=0.80$ \\
\hline \multicolumn{6}{|l|}{ Düşük sayısı } \\
\hline 0 & 118 & 87.6 & 176 & 78.6 & $X^{2}=4.71$ \\
\hline 1 & 23 & 10.4 & 39 & 17.4 & $p=0.09$ \\
\hline 2 ve üstü & 11 & 5.0 & 9 & 4.0 & \\
\hline \multicolumn{6}{|l|}{ Kürtaj sayısı } \\
\hline 0 & 210 & 94.6 & 203 & 90.6 & $\mathrm{X}^{2}=2.56$ \\
\hline 1 ve üstü & 12 & 5.4 & 21 & 9.4 & $\mathrm{p}=0.10$ \\
\hline
\end{tabular}

Araştırmaya katılan gebeliği isteyen ve istemeyen gebelerin TAS-20 ölçeği toplam puan ortalamasının karşılaştırıması Tablo 3'de verilmiştir. Gebeliğini isteyenlerin TAS-20 ölçeği toplam puan ortalamasının $65.04 \pm 11.83$, gebeliğini istemeyenlerin $65.37 \pm 11.15$ bulunmuştur (Tablo 3).

Tablo 3. Grupların TAÖ'nin puan ortalamalarının karşılaştıııması

\begin{tabular}{|l|l|l|l|}
\hline TAÖ & Gebeliği İsteyen & Gebeliği İstemeyen & Test ve p değeri \\
& & & \\
& $\bar{X} \pm \mathrm{SS}$ & $\bar{X} \pm \mathrm{SS}$ & \\
\cline { 2 - 4 } & $65.04 \pm 11.83$ & $65.37 \pm 11.15$ & $\mathrm{t}=0.19, \mathrm{p}=0.84$ \\
\hline
\end{tabular}

\section{TARTIŞMA}

Literatürde gebeliğin aleksitimi ile ilişkisini inceleyen sınırlı sayıda çalışmaya rastlanılmıştır. Bu yüzden çalışma benzer araştırma bulgularıyla tartışılmıştır.

Bu çalışmada TAS-20 ölçeği toplam puan ortalamasının her iki grupta benzer olduğu ve her iki grubun aleksitimik duygular yaşadığını ortaya koymaktadır. Bireylerin gebelik süreçlerini olumlu geçirme, bebeklerine olan bağlanma düzeyi ve aldığı sosyal destek kadının psikolojik durumunu etkileyen en önemli ölçütlerdir. Bu süreçte ruhsal durumlarının mümkün olan optimal seviyede tutmak önemlidir. Çalışmamızda görüldüğü gibi her iki grup gebelerde aleksitimik özellikler taşımaktadır. Aleksitimi ve prenatal dönem psikolojik rahatsızIıklar arasındaki ilişkinin incelendiği bir çalışmada gebelik sırasında aleksitimi skorları arasındaki korelasyon ve doğum sonu 2 aylık süre içerisinde elde edilen skorun 0.74 olarak bulunmuş ve ilişki olduğu saptanmıştır (27). Başka bir çalışmada antepartum dönemindeki gebelerde aleksitimi puan ortalaması $52.65 \pm 11.34$ olduğu bulunmuştur (28). İran' da yapılan bir çalışmada gebe kadınların aleksitimi prevalansı \%27.9 olarak bulunmuştur (22). Le ve ark.'nın aleksitimi ve perinatal depresif belirtiler arasındaki ilişkileri incelediği çalışmasında; gebelikte depresyon riski yüksek olan kadınların aleksitimi düzeylerinin düşük riskli kadınlara göre anlamlı derecede yüksek olduğu bulunmuştur (29). Daha önce yapılan araştırmalarla uyumlu olarak, antepartum depresif belirtiler için sosyal destek eksikliği, hamilelikte sigara içimi ve planlanmamış veya istenmeyen bir gebelik gibi çeşitli risk faktörleri bulunmuştur $(30,31)$. Karukivi ve ark.'nın aleksitimi ve doğum sonrası anksiyete ve depresyon belirtilerini incelediği kohort çalışmasında; aleksitimi ile daha sonraki ortaya çıkabilecek psikolojik belirtiler arasındaki anlamlı bir ilişki saptanmamıştır (31). Marchesi ve ark.'nı gebe kadınlarda çalışmış ve aleksitimi hastalarının panik bozukluğu gelişimine yatkın olmadığı sonucuna varmıştır (32)

\section{SONUÇ}

Çalışmamız gebeler üzerinde aleksitimi durumlarını değerlendiren ilk çalışma olması nedeni ile literatüre olumlu katkılar sağlayacaktır. Belirli bir bölgedeki gebelerden oluşmasından dolayı sonuçlarımızın tüm gebelere uyarlanabilmesi için daha geniş ve farklı bölgelere ait örneklemlere intiyaç vardır. Sonuç olarak; gebeliği isteyen ve istemeyen gebelerin aleksitimik özelliklerini karşılaştırmak amacıyla yapılan çalışmada grupların tanıtıcı özelliklerinin homojen olduğu ve aleksitimi düzeyleri arasında anlamlı bir fark olmadığı bulunmuştur. Gebelik döneminde ortaya çıkabilecek herhangi bir ruhsal durum bozukluğunun erken dönemde tanınmasında sağlık profesyonellerine büyük sorumluluk düşmektedir. Ülkemizde tarama programları başlatılmalı, rehberler geliştirilmeli, riskli gebeler erken dönemde tespit edilmelidir. Tespit ve tedavisi yapılmamış gebeler hem kendileri hem de bebekleri için risk oluştururlar.

Gebeleri ve lohusaları takip ve ev izlemleri düzenli yapılmalı ve kayıt altına alınmalıdır. Antenatal bakım kalitesi arttırımalıdır. Doğuma hazırık sınıflarında verilen eğitimlerle gebeler değerlendirilebilir. Aleksitiminin özelliklerini tanımlamada güçlük çeken gebelerin kendilerini ifade etmeleri için rahat bir ortam sağlanmalı ve fırsat tanınmalıdır. Ruhsal durum değişiklikleri hakkında bilgilendirmeler yapılabilir. Sağlık profesyoneli, gebenin sosyal destek sistemlerinin oluşmasını ve desteklenmesini sağlamalıdır. Ayrıca aleksitimik özelliklerin iyileştirilmesi için spesifik psikoterapötik tekniklerden (grup terapisi, bilişsel davranış̧̧ı terapi yaklaşımlarını, biofeedback, psikodrama vb.) yararlanılmalı ve böylece ruhsal durumun daha kötüye gitmemesi sağlanmalıdır.

\section{REFERANSLAR}

1.Eskici L, Demir Akca AS, Atasoy N, Arıkan I, Harma M. Gebelerde depresyon ve anksiyete bozukluğunun obstetrik sonuçları ve yenidoğan üzerine etkileri. Anatol J Clin Investig 2012;6(1):10-16.

2.Çalık KY, Aktaş S. Gebelikte depresyon: sıklık, risk faktörleri ve tedavisi. Psikiyatride güncel yaklaşımlar 2011;3:142-162.

3.Sevindik F. Elazığ ilinde gebelikte depresyon prevelansı ve etkileyen faktörler. Fırat Üniversitesi Sağlık Bilimleri Enstitüsü, Halk Sağlığı Anabilim Dalı, Yükseklisans Tezi, Elazığ, 2005

4.Ocaktan ME, Çalışkan D, Öncü B, Özdemir O, Köse K. Park Sağılk ocağ bölgesindeki gebelerde doğum öncesi ve sonrası depresyonun değerlendirilmesi. 4. Uluslararası Üreme Sağlığı ve Aile Planlaması Kongresi, 20-23 Nisan 2005, Ankara, Türkiye. Kongre Özet Kitabı Sayfa 277-278.

5.Levey L, Ragan K, Hower-Hartley A, Newport DJ, Stowe ZN. Psychiatric disorders in pregnancy. Neurol Clin. 2004;22:863-893.

6.Anderson L, Sundström-Poromaa I, Bixo M, et al. Point prevelance of psychiatric disorders during the second trimester of pregnancy: A population-based study. Am J Obstet Gynecol 2003;189:148-154.

7.Copoglu SÜ, Kokacya MH, Demircan C. Gebelik ve laktasyon döneminde ruhsal bozukluklar ve tedavisi. Mustafa Kemal Üniv Tıp Derg 2015;6(24):4353.

8.Özdamar Ö, Yılmaz O, Beyca HH, Muhcu M. Gebelik ve postpartum dönemde sık görülen ruhsal bozukluklar. Zeynep Kamil Tıp Bülteni 2014;45(2):71-7.

9.Bonnet A, Bréjard V, Pasquier A, Pedınıellı Jl. Affectivity and alexithymia: two dimensions explicative of the relationship between anxiety and depressive Symptoms. Encéphale. 2012;38(3):187-93. 
10.Tolmunen T, Lehto SM, Helıste M, Kurl S, Kauhanen J. Alexithymia is associated with increased cardiovascular mortality in middle-aged finnish men. Psychosom Med. 2009; 72(2):187-91.

11.Schwartz GE, Kline JP. Repression, emotional disclosure, and health: theoritical, empirical, and clinical considerations. In Emotion, Disclosure \& Health Washington: American Psychological Association Press 2002;(3rd Ed.):177-193.

12. Taylor GJ, Bagby RM, Parker JD. Alexithymia construct, a potential paradigm for psychosomatic medicine. The Academy of Psychosomatic Medicine 1991;32 (2):153-163.

13.Sifneos PE, Apfel-Savitz R, Frankel FH. The phenomennon of alexithymia: observations in neurotic and psychosomatic patients. Psychoteraphy And Psychosomatics 1977;28:47-57.

14.Şahin RA. Peptik ülser ve aleksitimi. Türk Psikiyatri Dergisi 1991;2(3):2530 .

15.Şaşıoğlu M, Gülol Ç, Tosun A. Aleksitimi: tedavi girişimleri. Psikiyatride güncel yaklaşımlar. Current Approaches in Psychiatry 2014;6(1):22-31.

16.Bankier B, Aigner M, Bach M. Alexithymia in DSM-IV disorder: comparative evaluation of somatoform disorder, panic disorder, obsessive-compulsive disorder and depression. Psychosomatics 2001;42:235-240.

17. Tolmunen T, Heliste M, Lehto SM, Hintikka J, Honkalampi K, Kauhanen J. Stability of alexithymia in the general population: an 11-year follow-up. Compr Psychiatry 2011; 52:536-41.

18.Batıgün $A D$, Büyükşahin A. Aleksitimi: psikolojik belirtiler ve bağlanma stilleri. Klinik Psikiyatri Dergisi 2008;11:105-14.

19.Ünal G. Bir grup üniversiteli gençte çekingenlik, aleksitimi ve benlik saygısının değerlendirilmesi. Klinik Psikiyatri Dergisi 2004;7(4):215-22.

20.Kaplan O. Pemfigus vulgaris etiyolojisinde psikolojik etkenler, algılanan stres ve ilişkili faktörlerin araştırıması. Haydarpaşa Numune Eğitim ve Araştırma Hastanesi, Uzmanlık Tezi, İstanbul: 2007.

21.Bağci T. Üniversite öğrencilerinin aleksitimi düzeylerinin bazı değişkenlere göre incelenmesi. Gazi Üniversitesi Gazi Eğitim Fakültesi örneği. Gazi Üniversitesi, Ankara, 2008
22.Gılanıfar M, Delavar MA. Alexithymia in pregnant women: its relationship with depression. ASEAN Journal of Psychiatry 2016;17(1):35-42.

23.Yürümez E, Akça ÖF, Uğur Ç, Uslu RI, Kılıç BG. Mothers' alexithymia, depression and anxiety levels and their association with the quality of mother-infant relationship: a preliminary study. Int J Psychiatry ClinPract 2014;18(3):190-6.

24.Bagby M, Taylor G. Construct validation. In: Taylor GJ, Bagby RM, \&Parker JDA, editors. Disorders of Affect Regulation. Alexithymia in Medical and Psychiatric illness. Cambridge, UK: Cambridge University Press 1997:46-66.

25.Güleç H, Köse S, Güleç MY, et al. Reliability and factorial validity of the turkish version of the 20-Item toronto alexityhymia scale (TAS-20). Klinik Psikofarmakoloji Bülteni 2009;19:214-20.

26.Güleç H, Yenel A. 20 maddelik toronto aleksitimi ölçeği türkçe uyarlamasının kesme noktalarına göre psikometrik özellikleri. Klinik Psikiyatri 2010;13:108-12.

27.Dunkel SC, Tanner L. Anxiety, depression and stress in pregnancy: implications for mothers, children, research, and practice. Curr Opin Psychiatry 2012;25(2):14-18.

28.Lancaster CA, Gold KJ, Flynn HA, Yoo H, Marcus SM, Davis MM. Risk factors for depressive symptoms during pregnancy: a systematic review. Am. J. Obstet. Gynecol 2010;202:5-14.

29.Le HN, Ramos MA, Muñoz RF. The relationship between alexithymia and perinatal depressive symptomatology. J Psychosom Res 2007;62:215-22.

30.Räisänen S, Lehto SM, Nielsen HS, Gissler M, Kramer MR, Heinonen $S$. Risk factors for and perinatal outcomes of major depression during pregnancy: a population-based analysis during 2002-2010 in Finland. BMJ Open. 2014

31.Karukivi M, Tolvanen M, Karlsson H, Karlsson L. Alexithymia and postpartum anxiety and depression symptoms: a follow-up study in a pregnancy cohort. J Psychosom Obstet Gynaecol, 2015;36(4):142-147.

32.Marchesi C, Giaracuni G, Paraggio C, Ossola P, Tonna M, De Panfilis C. Pre-morbid alexithymia in panic disorder: a cohort study. Psychiatry Res 2014;215:141-5. 